\title{
LAPAROSCOPY IN CHILDREN, A BRIEF OUTLINE AND BANGLADESH PERSPECTIVE
}

When it comes to health care delivery, people are now demanding an increase in quality and services and a decrease in cost. Increasing the quality of health care delivery may require that a health care facility invest in new technologies, which may be costly and often involves a steep learning curve for practitioners. Change is the only constant in health care, however, so practitioners need to be aware of the changes that are on the horizon for the health care industry and find ways to successfully deal with the inevitable challenges these changes will bring ${ }^{1}$.

The practice of surgery has changed dramatically over the past three decades. The two main driving forces behind these changes have been advances in medical technology and greater public expectations. Minimally invasive techniques such as microsurgery, fibre-optic endoscopy, laparoscopic and arthroscopic surgery and interventional radiology have broadened the range of

therapeutic options ${ }^{2}$. The types and number of minimally invasive or laparoscopic techniques increase every year. Although minimally invasive procedures were once considered merely a surgical trend, physicians in nearly all surgical specialties now are performing minimally invasive procedures on almost all anatomical areas ${ }^{1}$.

Laparoscopic surgery owes much of its history to the development of endoscopic technique. Early physicians such as the Arabian, Albukasim (936-1013 A.D.), and later in 1805, the Frankfurt-born physician, Phillip Bozzini, were among the first to develop methods to examine body orifices. The first effective open tube endoscope was developed in 1853 by Desormeaux and other physicians including Kussmaul and Nitze refined the original endoscopic models and began utilizing in their medical practice. Laparoscopy or endoscopically examinining the peritoneal cavity was first attempted in 1901 by George Kelling who called this examining procedure "Celioscopy". In the early 1930's, the first reports of laparoscopic interventions for nondiagnostic purposes were published. Initial procedures included lysis of abdominal adhesions and diagnostic biopsies of abdominal organs under direct visualization. Throughout the 1960's and 1970's, laparoscopy became a vital part of gynecological practice. Despite these technological advances, it was not until after 1986, following the development of a video computer chip that allowed the magnification and projection of images onto television screens, that the techniques of laparoscopic surgery truly became integrated into the discipline of general surgery ${ }^{3}$.

The first publicized laparoscopic cholecystectomy performed on a human patient was done in 1987 by the French physician Philip Mouret. The laparoscopic cholecystectomy is now considered standard therapy for routine gallbladder removal. The rapid acceptance of the technique of laparoscopic surgery by the general population is unparalleled in surgical history. It has changed the field of general surgery more drastically and more rapidly than any other surgical milestone, including the introduction of anesthesia and the later introduction of antibiotics ${ }^{3}$.

Dr Steve Gans, who described in the Journal of Pediatric Surgery in 1971 the use of what he called peritoneoscopy in children, considered as pioneer in the field ${ }^{4}$. Pediatric laparoscopic cholecystectomy was introduced by Holcomb et al. in 1991. The torrent of reports that followed expanded the applicability of pediatric endoscopic surgery to appendectomy, hernia repair, splenectomy, nephrectomy, pyloric stenosis, ovarian tumor, Hirschsprung's disease, fundoplication, etc. Endoscopic surgery for pediatric patients was a 
challenge for pediatric anesthesiologists as long as data were not available on physiological changes induced by carbon dioxide insufflations. It was also necessary to develop new instruments for pediatric endoscopic surgery, as treatment might be needed in children of all ages, including neonates ${ }^{5}$. However, thanks to the continued efforts from Keith Georgeson, Whit Holocomb, Steve Rotheberg and other pediatric surgeons across the world that Pediatric laparoscopy is now a well established surgical specialty.

Opponents were always there to denounce this technological advancement. Kurt Semm who was an engineer as well as a gynecologist had developed the CO2 insufflator and the Roeder loop. In 1983, he reported on the first laparoscopic appendectomy. Soon after this presentation, the leaders of the German Surgical Society demanded Semm's suspension from medical practice. His colleagues in his hospital proposed that he undergo a brain scan to see if his erratic and bizarre behavior of wanting to operate through a telescope was because of some organic and potentially remedial problem ${ }^{4}$. One Pediatric Surgeon recently raised these questions and tried to prove everything wrong 6 :

Is Pediatric Laparoscopy Minimally Invasive?

Is Laparoscopy Cosmetically Superior?

Is Laparoscopy Painless?

Is Laparoscopy Economical?

Is Laparoscopy Associated with Fewer Complications?

During the early periods of pediatric laparoscopy, these questions might have been valid. However, after a long journey and vast experience, we can say that pediatric laparoscopy is minimal invasive, cosmetically superior, less painful and economical with fewer complications ${ }^{7,8,9}$.

First laparoscopic cholecystectomy was done in Bangladesh back in 1991 by Sarder A. Nayeem and his team in an adult. However it took us a decade to start pediatric laparoscopy in Bangladesh. The author took the initiative, joined by Dr. Ashrarur Rahman and Dr. Arifur Rahman, went to Prof. Anirudh V. Shah in Ahmedabad, Gujarat, India for training. Back home, the first case (Laparoscopy-Assisted Orchiopexy) was done on $25^{\text {th }}$ April 2005 in Shishu Sashthya Foundation Hospital in Mirpur, Dhaka by Dr. Arifur Rahman and the author with the help of Dr. Aminur Rashid Minu, a general Laparoscopic Surgeon. Later on, the author started doing laparoscopy in children in Chittagong regularly since October 2005. Chittagong Medical College was the first to procure Pediatric Laparoscopic instrument in the government sector. Chittagong Medical College \& Hospital was also the pioneer institution in starting laparoscopic surgery in government sector led by Dr. Md. Ashraf ul huq Kazal. Thereafter all the old medical colleges and Dhaka Shishu Hospital got the instruments during 2005-6. Dr. Ashrarul Rahman Mitul and Prof. M.A. Aziz were the pioneer surgeons to start laparoscopy in Dhaka Shishu Hospital.

So far around 3300 laparoscopic procedures have been done in children in Bangladesh. The author's institution has done the majority (2235) followed by Dhaka Shishu Hospital (329), Shishu Sashthya Foundation Hospital, Dhaka (216), Chittagong Medicoal College (175), Dhaka Medical College (113), Square Hospital (96), Apollo Hospital (73), SSMC \& Mitford Hospital 45, Sylhet MAG Osmani Medical College (30), Rangpur Medical College (15). Majority cases are appendectomy; followed by inguinal hernia repair, pullthrough for HD, orchiopexy, pyloromyotomy, cholecystectomy, ovarian cystectomy and diagnostic etc.

From my own experiences, not because they were the most important but because they are what I know best, I can say that Pediatric Laparoscopy is now a well accepted modality of treatment among the physicians as well as general population in our country. However, for the survival of the specialty in the long run, we need new blood and that can be achieved with proper training. The authors' institute has got a facility for informal training on pediatric laparoscopy. So far two pediatric surgeons from Bangladesh (Dr. Abu Jafor and Dr. KMN Ferdous) and three from abroad (Nepal, Hungary and Switzerland) took the opportunity. Several workshops were organized in authors' institute, Chittagong Medical College and Dhaka Shishu Hospital to create interest and awareness among pediatric surgeons. Now is the time that we think about establishing a formal training program for our future generation. We really have to be careful of what we do because some of the enthusiasm can turn sour if not handled correctly. It is my observation that the initial enthusiasm has somehow abated and it is reflected in the number of cases performed in different centres of Bangladesh, although they have got basic laparoscopic set up. It is important for surgeons to recognize their limitations and to seek appropriate training and understanding of a new technique before they attempt it.

\section{Prof. Md. Jafrul Hannan}

Head, Department of Pediatric Surgery

Chattagram Maa-O-Shishu Hospital Medical College

Chittagong, Bangladesh. 


\section{References}

1. Catalano K, Fickenscher K (2007) Emerging Technologies in the OR and Their Effect on Perioperative Professionals. AORN J; 86: 958-969.

2. Cosman P, Hemli JM, Ellis AM and Hugh TJ (2007) Learning The Surgical Craft: A Review of Skills Training Options. ANZ J Surg; 77: 838845

3. Spaner SJ, Warnock GL (1997)A Brief History of Endoscopy, Laparoscopy, and Laparoscopic Surgery. J Laparoendosc Adv Surg Tech; 7 (6): 369-74

4. Georgeson K (2011) Pioneers, cowboys, and desperados: a brief history of pediatric surgical innovation. J Pediatr Surg; 46: 1-7

5. Sato M, Hamada Y, Iwanaka T (2010) Recent Progresses of Pediatric Endoscopic Surgery in Japan. JMAJ 53(4): 250-253.
6. V. Raveenthiran (2010) Pediatric laparoscopy: Facts and factitious claims. J Indian Assoc Pediatr Surg; 15(4): 122-128.

7. Hannan MJ, Hoque MM, Begum LN (2012) Laparoscopic appendectomy in pregnant women: experience in Chittagong, Bangladesh. World J Surg; 36(4):767-70.

8. Hannan MJ, Hoque MM (2011) Laparoscopic cholecystectomy without handling the cystic artery: a new approach to minimize complications. J Laparoendosc Adv Surg Tech. PartA; 21(10):983-6.

9. Hannan MJ, Haque AU. Hoque MM (2012) Cystoscopy-assisted percutaneous removal of impacted urethral stone: a case report. J Laparoendosc Adv Surg Tech. PartA; 22(2):18991. 